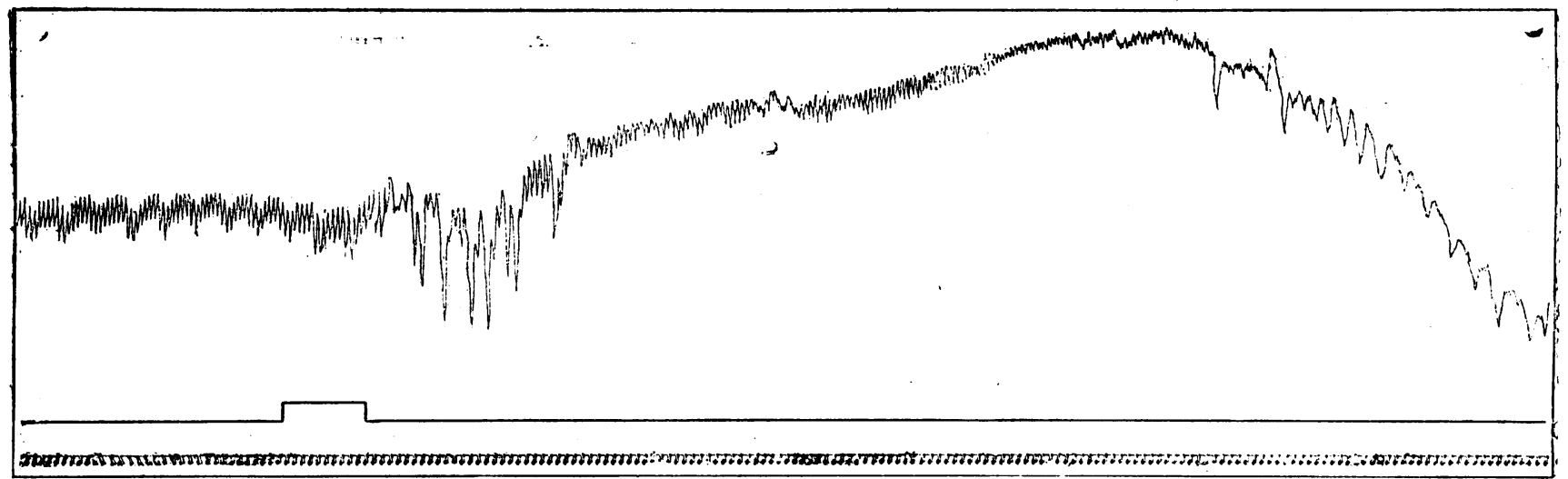

Fig. I.-Cat; ipoh, about $2 \mathrm{mg}$., injected into jugular vein.

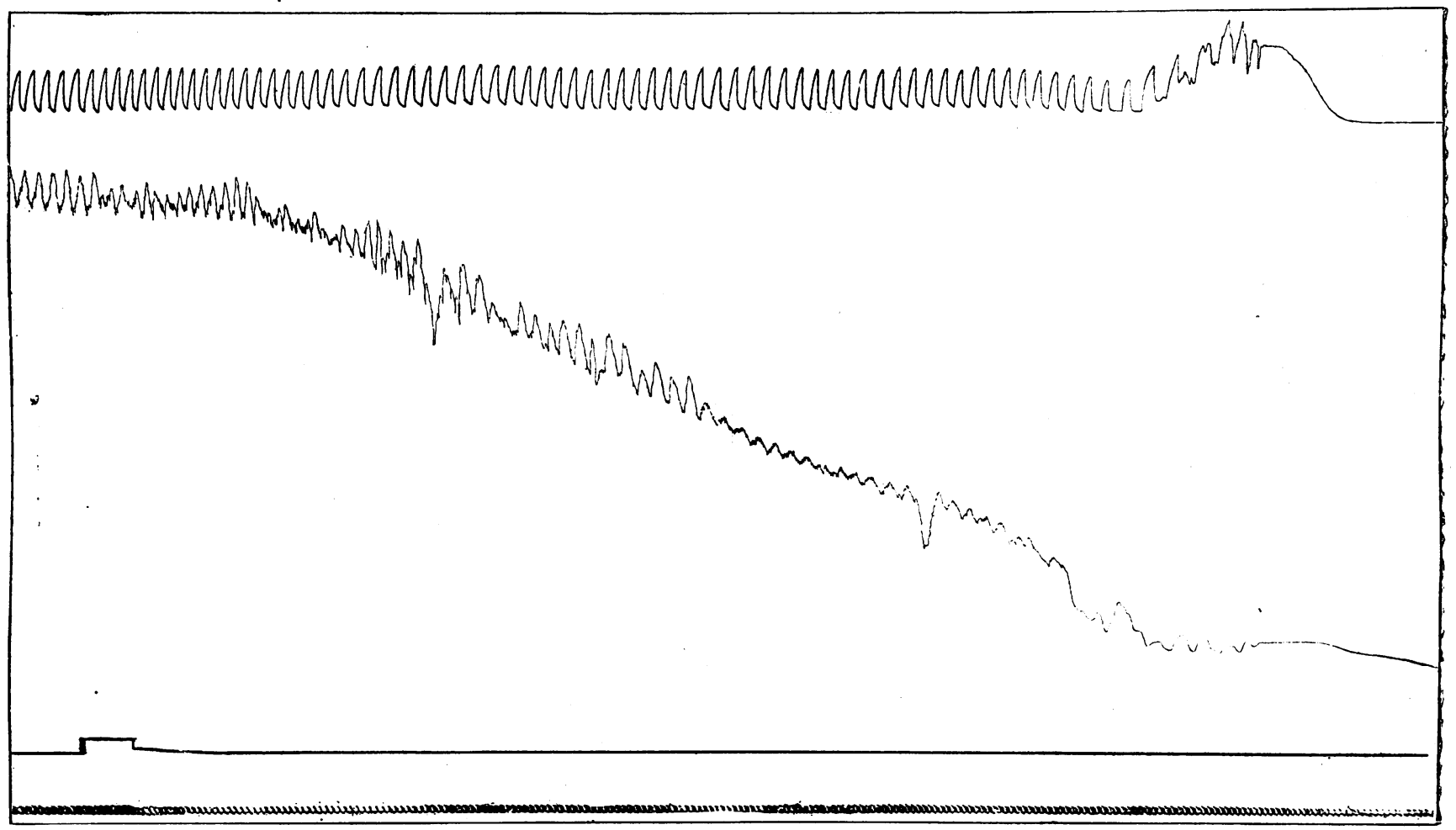

Fig. 2.-Gradual fall in blood pressure and late arrest of respiration brought about by the second of two injections of ipoh, each of $\mathrm{x} \mathrm{mg}$. 3 . It causes.passing clonic spasms of the voluntary muscles. When mammals or birds are subjected to its action marked gastro-intestinal symptoms are usually added to the above effects. Certain birds are, however, comparatively immune. My preparations of antiarin, a crystalline glucoside, the active principle of ipoh, lacked the convulsive effect of the crude substance, thus differing physiologically as well as chemically from Kiliani's antiarin, investigated by Hedbom, although in its purely cardiac toxicity it was at least as active as Kiliani's.

In conclusion, I wish to express my thanks to Dr. J. B. Leathes for much kind help and advice throughout this investigation.

Centenarians in the United States.-According to the United States census for 1900 there are 3,536 persons in the United States who are 100 or more years of age. The value of these figures is, however, somewhat discounted by the fact that 72.8 per cent. of the whole number are negroes; many are very hazy as to the date of their birth. It is improbable as pointed out by the Journal of the American Medical Association, that the United States should have over 3,500 centenaxians, when Germany, with a population of nearly $55,000,000$, has only 778 ; and England, with 32,000,000, only 146 ; and France, with 40,000,000, has only 213 .

\section{DRUG ERUPTIONS.}

By GEORGE PERNET, M.R.C.S.ENG., L.R.C.P.LoND., Assistant to the Skin Department, University College Hospital ; late Pathologist, Hospital for עiseases of the Skin, Blackfriars.

THE number of medical remedies which may give rise to rashes is a large and increasing one. Scarcely a week passes but some new synthetic product is placed upon. the market, usually accompanied by an assurance that it bas no drawback in the way of causing ill-effects. As a rule one has not to wait long before cases crop up which show that the new remedy is not so innocent as was at first supposed. Now many of these products are useful, but what I desire to emphasize is that they should be employed with care. Rather than give you a long list of drugs, with details of the cutaneous manifestations they may occasiop, I propose to take the various eruptions as they come before you clinically. This arrangement will be more practically useful, although it will necessitate some repetitions and cross-references owing to the overlapping of the morbid phenom $f$ na. It is the eruption we see, but the drug which caused it.we have to find out. I shall adopt the following rough, classification of the rashes : 
(s) Erythematous, urticarial, papular, and desquamating. (2) Vesicular and bullous, (3) Pustular. (4) Furuncular. (5) Purpuric. (6) Gangrenous. (7) Pigmentary and discolouring. (8) Hypertrophic. (9) Tumour-like.

1. Erythematous, Urticarial, Papular, and Desquamating Rashes.-These cutaneous conditions are those most commonly met with, as they are produced by the great majority of the drugs which give rise to eruptions. Belladonna.Applications containing it, such as glycerine of belladonna, have produced generalized symmetrical erythematous rashes of the limbs, with swelling and redness of the face, mixed up sometimes with erythema multiforme and wheal-like patches. Atropine ointment is in the same case. The itching is very great, and it may be said at once that this is a common symptom in eruptions of this kind. Belladonna by the mouth may lead to a scarlatiniform rash, but it is rarely seen, although the drug is freely prescribed. Other solanaceous plants act in the same way. A purplish rash all over the body, with much swelling of the face, followed the ingestion of an ounce and a half of tinct. hyoscyami taken in mistake for a black draught. ${ }^{1}$ Chrysarobin is another drug which leads at times to a marked diffuse erythema, especially when applied near the face. In this situation it is frequently accompanied by a smart conjunctivitis. Mercury, locally applied in the shape of ointment, is well known to give rise to an.eruption, which may be anything from a slight erythema to a severe eczematous-like, irritant dermatitis, according to the strength of the preparation and the suscep tibility, of the patient; such a rash may become generalized, and cases have been recorded of pityriasis rubra, that is, a universal dermatitis, supervening with a fatal result. In the old days when mercury was used in a wholesale manner, the cutaneous complications were very severe and frequent, and went by the name of hydrargyria, morbus mercurialis, etc. Alley saw forty-three cases in ten years, and eight of these terminated fatally. ${ }^{2}$ In this condition there was diffuse redness of the skin, with tumefaction, tenderness, and itching, accompanied by the formation of pinhead-sized vesicles, with weeping. The whole body became involved. It usually terminated by desquamation, the epidermis coming off in large flakes. In some instances the nails and hair fell off. Such severe cases are very seldom seen now. It is an interesting point that these mercurial rashes when they occurred in the course of syphilis were attributed to the lues venerea itself, with the unfortunate result that the mercury was pushed with greater energy in proportion to the severity of the symptoms. It was in this way that a fatal termination sometimes ensued. But the fact that eruptions were occasionally met with in patients who were not suffering from syphilis, and were taking mercury for other complaints, led observers to the discovery that the eruption was entirely due to the drug. This fact was published by Alley in 1804 , but Pearson claimed he had known the disease hydrargyria ever since $178 \mathrm{I}^{3}$ Mercury by the mouth may also give rise to various rashes, and they have been observed to follow also intramuscular injections and intrauterine and vaginal douches. A localized dermatitis is occasionally seen to result from the use of unguentum hydrargyri for pediculi pubis. At one time, when blue ointment was used in a routine manner for this complaint, such a complication was common.

Arsenic during the Manchester beer poisoning epidemic produced a variety of rashes. Brooke and Roberts have described erythematous eruptions on the trunk, which were either diffuse (scarlatiniform, morbilliform, erythrodermial) or circumscribed (papular, circinate, etc.). Urticarial wheals w.ere also seen, and the cutaneons lesions sometimes simulated seborrhoeic dermatitis, psoriaris, lichen planus, and papular syphilides. The hands and feet were hot, swollen, and painful, with redness of the palms and soles, accompanied by marked hyperidrosis of the latter. Of course, in the development of these rashes, the association of two poisons must be borne in mind in the estimation of the results of the Manchester chronic intoxications.

Iodoform, when used locally, is well known to act as an irritant in some patients. When it has been absorbed, urticarial and erythematous condition have occurred. The substitutes for iodoform (europhen, loretin) may also act as irritants. Orthoform applied locally has led to erythematous and erythemato-papular eruptions; and also to more severe conditions. I have seen insufflation into the nares followed by marked swelling and redness of the face.

Copaiba may cause an eruption which at times leads to errors of diagnosis. It may be papular, scarlatiniform, or morbilliform. Usually it is made up of rosy red, slightly. elevated patches, chiefly about the backs of the hands, the fronts of the knees, the limbs, and abdomen. A well-defined scarlatiniform rash may develop over the front of the trunk. Turpentine by the mouth has also given rise to erythematous and morbiliform rashes.

Quinine and salicin are two drugs with similar effects. Quinine erythema may supervene in patients with a generalized skin disease, such as psoriasis. This is rarely met with and, indeed, in widespread inflammatory skin affeetions, such as pityriasis rubra, generalized eczema, etc., the effects of quinine are distinctly beneficial. With salicin a rash is an extremely rare complication.

Borax, once much used in epilepsy, has been said to have caused psoriasis. I have never seen this, and the question arises whether the rash was true psoriasis, or only psoriasiform. And further, if true psoriasis, was the borax the essential cause of it or merely a factor in its development, or was the eruption quite independent? Boric acid has given rise to erythema and other rashes after washing out purulent cavities, but the poesibility of absorption of toxic products must not be forgotten in such cases. . Rashes have also followed jts use in washing out the stomach, after rectal injections, etc.

Erythematous eruptions may be caused by a number of drugs -opium, morphine, potassium chlorate, digitalis, etc. The numerous synthetic remedies also act in this way : antipyrin. phenacetin, sulphonal, etc. Chloral hydrate deserves special notice. The eruptions from the use of this drug vary, but are usually erythematous in type. They occur, too, as dusky-red papules, or as a purplish mottling in the neighbourhood of the joints of the extremities. The scarlatiniform rashes may be generalized, with flushing of the face, itching and burning, and followed by desquamation. I may remind you, too, of the erythema which occurs in ether and chloroform anaesthesia, and also of the well-known antitoxin rashes.

\section{Diagnosis.}

Diagnosis in the foregoing cases may be easy, at other times difficult. In scarlatiniform rashes the first thing is to exclude scarlatina. Here duration, mode of onset and development, and absence of corroborative symptoms are the points to lean on. Non-scarlatinal rashes do not usually come out in the order observed by scarlatina. There may be some rise of temperature and some congestion of the fauces in the former, but this is not the rule. I need scarcely insist on the importance of examining the urine in suspected scarlatina. Desquamation is not the appanage of scarlatina ; it occurs also to a greater or less' extent as a result of scarlatiniform rashes in general. In times of small-pox epidemics the premonitory scarlatiniform rash of that disease, which sometimes occurs about the abdomen, must be thought of. Scarlatiniform eruptions due to food poisoning, resulting from prolonged constipation, or following the absorption of toxic bodies liberated by enemata, or occurring in the course of gonorrhoea at times, may be mentioned here, as also the idiopathic ergthema scarlatiniforme, so called when the cause cannot be made out. M:altiformity is in favour of non-scarlatinal rashes-that is, the coexistence of urticaria, erythema multiforme-like patches, and so forth. Morbilliform eruptions must be dealt with in the same way. In urticarial cases animal parasites would have to be excluded, as also hepatic and renal defects.

Erythema multiforme has been closely imitated by drug rashes. In the areenical beer-poisoning epidemic the grouped papules observed in some cases about the limbs bore a great resemblance to those of erythema multiforme, which was increased at times by the depression and bluish discoloration of their centres. When psoriasis, lichen planus, syphilides are simulated, the duration, distribution, character of the lesions, and corroborative symptoms, as adenitis in the case of syphilis, must be carefully gone into and these diseases excluded. Pityriasis rosea would be put out of court by the fact that it usually commences as a single primary patch, followed alter some days by a rash about the body and upper segments of the limbs, consisting of fingernail-sized, rosy red patches, oval or circinate, with very fine desquamation. Having got rid of the above possibilities, the offending drug must be traced. I may at once say that cross-examination as to previous treatment, or as to whether the patient has been taking drugs on his own account, will not always elicit the cause. In the latter case patients do not always admit having taken quack remedies. Headaches would make one think of antipyrin or other headache "cure;" insomnia, of chloral hydrate, etc. Some people, again, are fowd of trying their friends' 
prescriptions. When copaiba is suspected, a gonorrhoeal discharge will be of assistance. In a dermatitis localized to the pubic regions and groins, the pediculus pubis should be looked lor, about which the patient has, perhaps, not eaid a word, nor of having used mercurial ointment. In atropine rashes. dryness of the mouth and dilatation of the pupils would perhaps be present. I have noted the former symptom in one case, but there was some doubt about the latter, as a certain amount of dilatation is habitual in some individuals. In eases of accidental or euicidal poisoning corroborative evidence. such as bottles, etc., would help.

2. Vesicular and Bullous Eruptions.-Vesicular and bullous lesions are at times mixed up with erythematous and papular manifestations, and indicate a more severe action of the drug or a greater susceptibility of the skin. This may be compared with what is observed in the erythems multiforme group in which we get a variety of eruptive elements-papules, vesicles, and bullae. In the rashes under review there is often a preponderance of one or other of these primary lesions ; in some cases the eruption may be practically made up of one kind. Vesicles and bullae have been observed in rashes originated by most of the drugs I have already alluded to, such as antipyrin, arsenic, copaiba, chloral hydrate, morphine, mercury, quinine, salicylates, etc. In this place several deserve special mention. Thus iodoform applied locally to varicose ulcers for instance, occasionally leade to a vesicular eruption characterized by closely aggregated vesicles on an erythematous base, with at times formation of bullae by coalescence. In some instances. the eruption is eczematous, but in several I have observed the vesicles were hemp-seed and larger in size. The rash is not limited to the neighbourhood of the immediate source of irritation. Mr. Hancocke Wathen has recorded his personal experiences of iodoform dermatitis, which in his case led to the formation of blebs about the hands after merely handling iodoform gauze. The eruption suggested pompholyx. It was only after several attacks that the condition was traced to the gauze. ${ }^{4}$ Other surgeons have had a similar experience, and have had to give up the use of the drug in their work.

Salipyrin (a compound of salicylic acid and antipyrin) has led to a herpes-like eruption about the glans penis and mucous membranes of the mouth. There were also erythematous areas about the hands and upper limbs in the case of a medical man, who had taken 15 grains in a little diluted cognac. He found subsequently that a very small dose of antipyrin had the same effect. There is an interesting case of a German student, who for about nine months had recurrent attacks of a bullous exanthem involving various parts of the body, but chiefly the face. This was accompanied by headache, rigors, and pyrexia. The diagnosis of pemphigus chronicus was made, but it turned out subsequently that this rash occurred after drinking bouts, the patient treating the usual Katzenjammer in the morning by taking 30 grains of antipyrin in place of the customary red herring. Here again the combination of beer and drug may account for the severity of the symptoms.

It is important to mention that bullous eruptions are greatly aggravated by the exhibition of potassium iodide. The drug should never be given in such cases. I have aiso seen what appeared to have been originally an erythema multiforme made markedly bullous by small doses of potassium iodide combined. with mercury under the impression that the patient was suffering from syphilis. This mistake is also very likely to occur in cases of non-syphilitic vesicu!ar eruptions about the mucous membranes of the mouth, in which case both mercury and iodide would make matters worse, especially if pushed. Just as in the old days mercury was persevered with in mercurial exanthems mistaken for manifestations of syphilis, so at the present time the cause of the aggravation by iodides is apt to be overlooked, and the drug given in increasing doses, thus adding fuel to the fire and establishing a vicious circle.

That arsenic may give rise to zoster was first pointed out by Mr. Jonathan Hutchinson, and it has since heen confirmed by a number of other observers. This fact has proved of great practical importance, for it was zoster which first suggested to Dr. Ernest Reynolds the possibility of arsenic in the beer being at the bottom of the Manchester poisoning epidemic. ${ }^{5}$ Apart from zester, vesicular and bullous eruptions were rare in the Manchester epidemic, but they have occurred more frequently in other arsenical poisoning epidemics. Zoster has also been seen in chorea treated hy arsenic. I have known of an attack of zoster in an elderly gentleman, who had been taking a course of areenical waters; there was marked neuritis, and it is probable that arsenic was the fons et origo mali.

The eruption caused by potassium iodide is more commonly pustular, but vesicles and bullae are sometimes seen. In this connexion it is important to distinguish between the lesions that are truly bullous and those which are only apparently so. In a case of Dr. Radcliffe Crocker's, the eruption was bullous to the eye, but when the lesions were punctured they were found to be solid. ${ }^{6}$ On the other hand, true bullous lesions may occur. This may perhaps be accounted for by the continued use of the iodide, notwithstanding the presence of an iodide rash. In several cases on record there was renal and cardiac disease, and therefore faulty elimination. Papules and pustules may be present at the same time as the bullae. Similar lesions may follow the exhibition of bromides.

As to diagnosis,, I need not repeat what I have already said. Iodide eruptions, consisting of papules, pustules, and bullae. have been sent in to hospital as cases of small-pox. It is of course of great practical importance to avoid erroneously diagnosing syphilis in these cases, a mistake which has been made, especially when the mucous membranes of the mouth have been affected. Pemphigus neonatorum and congenital bullous syphilides are not likely to be taken for drug eruptions.

Antipyrin may give rise to an erythema multiforme bullosumlike rash. A point about antipyrin is the pigmentation which may be left behind after the subsidence of the bullae. This pigmentation must not, in the absence of corroborative symptoms, lead to the erroneous diagnosis of syphilis. The recurrent vesiculo-bullous lesions due to iodoform must be specially borne in mind, and direct inquiry be made, especially in the case of medical men, for the cause of these rashes may be easily overlooked and ascribed to constitutional conditions. In fact surgeons, who have suffered in this way themselves, have failed for a long time to realize the cause of their trouble.

3. Pustular Eruptions.-Before considering the important bromide and iodide rashes belonging to this class, I will clear the ground by saying at once that arsenic, chloral hydrate, salicylic acid, etc., have led to lesions of this kind, but it is rare for this to occur.

Bromides. and especially potassium bromide, for it is the salt most frequently used and the one most potent for evil, give rise to pustular lesions, which may be either discrete or confluent. The discrete or acneiform condition is observed on the face, back, chest, scalp, and about the limbs, especially the legs. The rash consists of yellow pustules, from a hempseed to a pea in size, situated on a reddened base. Perseverance with the drug will increase the severity of the eruption. giving rise to the enlargement of the individual elements and to their confluence. In some cases ulceration has occurred, with subsequent formation of disfiguring scars. In infants and children confluence is the rule. In these cases, the markedly raised, more or less convex elevations of a reddish or violaceous hue, generally round or oval in outline, but sometimes with a gyrate border, and topped by small, closel y aggregated pustules, are characteristic. Moreover these lesions are soft and rather fluctuating to the touch, but they may have a more solid feel. An eruption of this kind may look very formidable, but when the offending drug is left of the elevations gradually subside, leaving no scar but merely a stain, which is at first purplish, then brownish, and remaining for some time as a record. Such lesions may occur quite in dependently. On the other hand, they are sometimes grafted on an existing dermatitis - no doubt a favouring circumatance a case of locus minoris resistentiae. In some instances marked papillary hypertrophy has developed in connexion with the elevated lesions just described; and there may also be a certain amount of scabbing in the central part. Radcliffe Crocker insists on their tendency to appear in scar tissue, such as vaccination scars, for instance. In addition to the confluent lesions, it is not unusual to find a few discrete acneiform pustules here and there.

The diagnosis of bromide rashes is one of great importance. A not uncommon error is to mistake them for syphilis, a great point being made of a negative history as to the administration of bromides. Histories, however, are fallacious, and it is well not to lean too hard on them. The confluent rash in children is characteristic, and it is important in such a case not to be misled by the negative replies of the mother, for cross-examination will often bring out the fact that the infant has had a soothing $\sim$ draught, or has been suffering from whooping-congh. Although there may be suspicions of 
syphilis about the mother, the objective appearances of the eruption must not be lost sight of for a moment. Moreover, there is nothing a priori against a syphilitic child having a bromide rash. In a case which had been diagnosed as a generalized vaccinia, and in which the history of bromide administration to the infant was negative, I was able to show, first, that the mother was suckling her infant; and, secondly, that she was herself regularly taking medicine for " fits"-a fact which she admitted very reluctantly. I mention this merely to emphasize the importance of bearing in mind the possibility of drugs being conveyed to sucklings through the mother's milk. Of course it is in epileptics that such eruptions are likely to occur. The addition of liq. arsenicalis to the bromide usually prevents the eruptions due to the latter drug, but not always, for they may occur even then, especially in a susceptible individual. In this connexion it should also be mentioned that in trying to avoid Scylla we must not fall into Charybdis-in other words, produce arsenical rashes. Another point about bromides is that the rash may continue to appear though the drug be stopped. This can be explained by the fact that bromides, and iodides also, have a diuretic action, the diuresis ceasing with their suppression. It must be borne in mind also that bromides are also frequently given for menopause and other neuroses, menstrual troubles, and so forth ; and that the various quack "I cure fits" remedies contain bromides. In a remarkable case of Szadek a medical man was treated for three years for a supposed recurrent syphilitic rash, which turned out to be really of bromide origin. ${ }^{8}$ In the case of a child who came under my observation, on my calling the attention of the medical attendant to the nature of the rash, he found that, quite unknown to himself, the single gr.v dose of bromide he had ordered originally had been continued nightly for several weeks.

The iodide pustular rashes are the most ccmmon. The individual lesions generally are smaller than in the case of bromides ; they are usually discrete, rarely confluent. Both these drug eruptions have points of resemblance, and affect mach the same parts of the body. Like the bromide rashes, those due to iodides may become very formidable-looking when they are pushed, as in the case of supposed syphilis, when the vicious circle I have already referred to may be established. Severe ulcerations may result, nodules may form, and also tumour-like masses. Individuals are, however, occasionally met with in whom iodides lead to an aggravation of syphilitic lesions, and it is in such that the noxious effects of the drug must be borne in mind. A common iodide rash is a pustular folliculitis, chiefly affecting the face, which the French call iodide acne. The lesions are more acute in development and more inflammatory, as a rule, than those of ordinary acne vulgaris, when severe scarring may ensue. Acne rosacea and acne vulgaris may be aggravated by its use.

As to the diagnosis of pustular iodide rashes, syphilis, when suspected, can be excluded by a careful examination and the absence of corroborative symptoms. The pustules due to the drug are usually more superficially seated than in syphilis, and do not, as a rule, leave a scar. Another point is that the iodides have a tendency to produce bullous lesions; and papules, pustules, and bullae may all be present at one and the same time. This multiformity of iodide lesions must not be mistaken for syphilis. The various advertised blood mixtures are frequently at the bottom of the mischief, for they contain potassium iodide. Patients do not always tell us what they have been taking on their own account, and, further, when examined on the point, they may be a long time admitting the fact. They may perhaps deny it altogether. The examination of the urine for iodine would in some cases be of assistance.

4. Furuncular complications sometimes result from the use of arsenic, bromides, and quinine. In this connexion I would call your attention in passing to the abscesses which may occur as an indirect result of self-administered morphine injections, due to unclean needles and the absence of aseptic precautions. Recurrent lesions of this kind localized to those parts where such injections are usually made should make you think of this possibility. Recent punctures may be present. In such cases there may also be diffuse infiltration of the skin, with multiple scars and some pigmentation.

5. Purpuric eruptions indicate a greater severity in the toxic effects, which may be due either to larger doses of the drug or to the greater susceptibility of the patient or of his tissues. As to the last-named point, the question of haemophilia as a factor would have to be gone into. Purpuric drug rashes are fortunately uncommon, but they have been observed after the exhibition of many of the remedies I have already referred to, such as antipyrin, arsenic, iodoform internally, quinine, sulphonal, etc.

In the diagnosis of these, purpuric lesions due to other causes must be excluded. They are numerous, and I may remind you in passing of the haemorrhagic skin manifesta tions which occur in typhus, in the premonitory rashes of variola, and also in other specific fevers and septic diseases. As a result of snake poison they are well known. To enumerate all the conditions in which they may occasionally occur would take us over a great part of the field of medicine. In the differential diagnosis the general condition of the patient must therefore be carefully gone into. The examination of the urine is especially important here. The duration, distribution, and the general symptoms would help in arriving at a conclusion. It must not be forgotten, however, that, given a cachectic condition, the exhibition of a drug may give rise to a rash. I have known potassium iodide produce a purpuric eruption in an advanced case of leprosy, in which the skin lesions were attributed to syphilis. In the case of haemorrhagic cutaneous lesions due to drugs, the distribution would be the same as that already described for the other kinds of rashes, but the lower limbs are more prone to purpuric conditions. Erythema multiforme sometimes assumes the haemorrhagic form (erythema purpuricum or haemorrhagicum), but with distinct elevation of the lesions, as opposed to the purely purpuric which are level with the skin. In both cases the lesions do not disappear on pressure. In both cases, too, the cause is no dnubt toxic. The condition known as peliosis or purpura rheumatica comes into the category of the exudation erythemata.

Sir J. Crichton-Browne has seen the long-continued use of chloral hydrate lead to purpura, which in one instance terminated fatally. ${ }^{10}$ Haemorrhage into bullae may also occur, as was the care in a lady under Wiglesworth, who had been taking bromides for a long period. ${ }^{11}$ Purpuric rashes have also heen seen after quinine.

6. Gangrene. - The onslaught on the skin may be so violent as to destroy its vitality. A complication of this kind has been seen after arsenic. iodide, quinine; and also after orthoform locally applied. Here again various factors are at work large doses, lnng continued use of the drug, vulnerability of the patient. In the case of arsenic the gangrene is more prone to attack the genitalia, but is not confined to them; it is an unusual condition. Arsenical zoster may go on to localized gangrene.

Potassium iodide has led to sloughing about the sites of bullae caused by it, with destruction of the penis. Such an experience emphasizes the importance of discontinuing the use of the drug when bullae occur, and of strictly avoiding its use in bullous eruptions. The local application of orthoform has been observed to give rise to gangrene. Dubreuilh has collected several cases in his paper on orthoform eruptions. ${ }^{12}$ Vincent has recently recorded a case of gangrene of both nipples in the puerperium, which I consider was due to the orthoform dressing. ${ }^{13}$ The anaesthetic effects of orthoform are interesting in this connexion, and the lowered vitality ending in gangrene may perhaps find an explanation from this property of the drug. Gangrene following a purpuric eruption apparently cansed by salicylate of soda has been published by Shepherd of Montreal, ${ }^{14}$ and a similar complication has been seen after quinine.

In the diagnosis of circumscribed areas of gangrene, feigned eruptions must be considered. I will merely allude in passing to diabetic gangrene, a condition well known to you. In the case of gangrene due to a drug locally applied, such as orthoform, the diagnosis should not offer much difficulty. As to drugs taken by the mouth, there would probably be other cutaneous manifestations, such as purpura, bullae, and so forth, to point in the right direction. The distribution and duration of the rash, and the general condition of the patient requiring the use of quinine, sodinm salicylate, etc., would help in coming to a conclusion. The multiple gangrene of infants and children would be excluded by attention to the appearances of the lesions and the development of the eruption.

7. Pigmentation.-This is a condition of particular interest and importance. That pigmentation may be caused by the prolonged use of arsenic in small doses has been long known. Hunt in 1847 stated that in persons of fair complexion and delicate skin arsenic commonly produced a dirty brown, dingy, unwashed appearance of all those parts of the body protected from light and air. ${ }^{15}$ I may say at once that fair people with delicate skins are not the only ones to be affected in this way. Indeed, Reynolds says it is not generally present 
in light-complexioned patients, but is practically always found in dark people. ${ }^{18}$. The Manchester epidemic has lately brought the subject prominently before the medical profession. Arsenical pigmentation usually affects the covered parts of the body, especially the abdomen and other parts of the trunk, with accentuation about the axillae and inguinal regions. It is frequently observed about the neck, where it attracts the aitention of the dermatologist and leads to further investigation. The limbs are sometimes more or less involved, and more rarely parts of the face also. In colour it varies from some shade of sepia to a blackish hue. In the early stage the follicles are spared, giving rise to a characteristic appearance of white dots on a dark ground. This can be well seen on the abdomen. In time the discoloration becomes uniformly diffuse.

According to Reynolds, in most cases the pigmentation follows the erythematous blush, which gradually turns from red to copper colour, then to bronze, and, in severe cases, almost to black. I would point out that another factor, namely, beer, in the Manchester cases must not be overlooked. It is possible, too, that where there is no diseased condition in which aisenic is known to act beneficially, the drug having no morbid change to expend itself upon, the normal tissues have to bear the whole brunt of its energies. The pigmentary changes due to arsenic may also occur in spots and patches varying in size. As to the diagnosis, all the facts must be taken into account. As far as objective symptoms go, chorea is an important one, as it is a condition which is treated in a routine way by arsenic. In this connexion I may allude to the "intensive" treatment recommended by Dr. W. Murray, of Newcastle, namely, large doses ( $m \times v)$ of liq. arsenicalis three times a day for a week only, the drug being then stopped. ${ }^{17}$ The latter point may be overlooked, and these large doses continued for longer periods with toxic effects. The association of the pigmentation with peripheral neuritis, or with rashes such as I have dealt with; also with oedema of the face and limbs, which was frequently met with in the beer-poisoning epidemic; and with other results of arsenical intoxication, hyperidrosis of the palms, and especially keratosis, with alterations in the texture of the nails, which $I$ will deal with presently, would be valuable in the way of corroboration, but the pigmentation may exist apart from other skin changes. The urine would perhaps contain a trace of albumen, and perhaps the test for arsenic would give positive results; this reaction was present in several of the Manchester cases. The history of epilepsy is very valuable. Sir William Gowers states that few patients who take the combination of potassium bromide and Fowler's solution for more than two years escape pigmentation. ${ }^{18}$ It must be remembered, too, that arsenic is also exhibited over long periods in other chronic nerve complaints; that it is used as 2 tonic in malaria; and last, but not least, that arsenic is erroneously looked upon as a kind of panacea in a variety of diseases of the skin. Patients again may go on using an arsenical prescription for considerable periods on their own account without troubling to report themselves in any way. Or they may pass a prescription on to a friend supposed to be suffering from the same complaint as themselves. But as I have already said, what we can see for ourselves is the chief thing to depend on. The minute white dots on dark background are characteristic. As to the differential diagnosis, the discoloration of the skin in Addison's disease is more uniformly diffused about the entire body, whereas arsenical pigmentation is irregular in its development. In the former disfase the mucous membranes are affected, the face involved, and the patient is weak, emaciated, and cacheticlooking, with almost next to no pulse from time to time, to say nothing of the vomiting often present. A common cause of very marked pigmentation is chronic pediculosis corporis, such as is frequently seen in Poor-law infirmaries; I mean the so.called vagabond's disease. Melano-leucoderma is another disease which must be excluded. It is more or less symmetrical and often well marked about the backs of the hands. It consists of abnormally white pigmentless areas which gradually encroach on the surrounding dark background. Leucoderma syphiliticum of the neck met with in eyphilis occasionally is more common in women than men. In such cases corroborative symptoms of syphilis would no doubt be forthcoming if carefully looked for. As to patchy arsenical pigmentation, which is more uncommon, it must be remembered that psoriasis treated with arsenic may leave pigmentation of the psoriasis areas behind after their involution. A point to be borne in mind again is that syphilis is not the only disease leading to pigrentat on. Antipyrin is another drug which gives rise to permanent pigmented areas. This condition has been named by Brocq eruption érythemato-pigmentaire fixe. ${ }^{19}$ It is described as occurring in roundish or oval patches up to a crown in size, at first pale red, but soon becoming deeper in tint, of a brownish-red or even blackish, reminding one of impending gangrene. Pigmented macules remain behind, and if antipyrin be again taken, the same macules brighten up, and on sabsiding become more pigmented than before. Antipyrin is not the only drug to do this, for phenacetin, acetanilid, and allied bodies have been found to act similarly. ${ }^{20}$

At one time nitrate of silver was much used for epilepsy. When continued in small doses for long periods a bluishness of the skin sometimes ensued. The discoloration is of a slate colour and is the result of the deposition of the metal in the tissues. The face and hands are most affected, that is, the parts most exposed to light. It has been said to follow longcontinued topical application of the salt to the throat. The condition is practically incurable, although improvement has been claimed by some observers. It is very rarely seen now. I have seen one case.

8. Keratosis or Hyperkeratosis. - This complication is observed in arsenical intoxication. It consists of a thickening of the horny layer of the epidermis chiefly about the palms and soles. Hyperidrosis of these parts has already been referred to in connexion with arsenic. The keratosis takes place about the sweat orifices. In the earlier stage a distinct thickening in this situation can be made out by careful examination with a lens. The changes must be looked for on the top of the epidermal ridges where the sweat ducts open. The appear as minute warty-looking lesions, which by increasing in size and coalescence form flat or nodule-like growths. They may also occur about the knuckles. They are characteristic and point to areenic as the cause, although a history may not be forthcoming. In the Manchester epidemic there was also redness, with tenderness, and other nerve symptoms reminiscent of the condition known as erythromelalgia.

The diagnosis depends on the points 1 have mentioned. Arsenical pigmentation may coexist, and be a valuable confirmatory point. It is sometimes necessary to distinguish arsenical keratosis from other plantar and palmar horny thickenings, such as the condition known as symmetrical keratodermia, in which there is marked general thickening of the afore-mentioned parts, whereas in that due to arsenic the central trianglf $s$ of the palm are spared as a rule, the brunt of the change falling on the thenar and the hypotbenar eminences. Of course, coalescence in the latter condition may give rise to uniform thickening more or less irregular in shape, the characteristic feature of the sweat orifice localization being lost. Moreover, symmetrical keratodermia (or keratoma palmae et plantae hereditarium) is a family complaint. It has been pointed out by Mr. Hutchinson that arsenical keratosis may lead to epithelioma. I am able to show you sections from a case under Dr. Radcliffe Crocker, in which the epithelioma supervened forty years after the arsenic had been discontinued. The drug had been originally taken for psoriasis. ${ }^{21}$ It may be that the thickened horny layers force the proliferating epithelial cells to grow downwards, and invade the corium, especially if the latter became lowered in vitality, as with advancing age, or as a result of cachectic diseases.

9. Tumour-like lesions may result in some cases. This is especially likely to occur in the bromide eruptions if the drug be persevered with. Köbner has recorded an instance of such a lesion being taken for a malignant growth and an amputation of the leg nearly proceeded with. Fortunately for the patient the true nature of the case was recognized at the eleventh hour. ${ }^{22}$ Similarly this eruption may be mistaken for mycosis fungoides ; the latter disease has also been simulated by the lesions produced by potassium iodide. This drug may occasionally give rise to subcutaneous nodular masses, which may or may not break down, and look something like sarcomata. In another case large red tumours formed about the body, limbs, and face with a fatal result. It is important, therefore, to bear in mind the possibility of such complications as a result of drug-taking.

Nails and Hair.-It is a well-known fact that arsenic is eliminated through these structures. Cases are on record in which arsenical poisoning has led to the loss of boch the hair and the nails.

With regard to the nails, ${ }^{23}$ waviness and roughness of their surface, longitudinal striations, discoloration, increased brittleness, etr., mav nccur. In snme cases hyperkeratosis of the nail be takes place, with raising of the nail plate. There is, 
however, nothing characteristic about such changes. Various conditions may lead to thcm, so that in arriving at a diagnosis all the facts must be taken into consideration. The association of pigmentation or of hyperkeratosis of the palms, neuritis, and so forth, would be in favour of an arsenical origin. The nails have also been shed as a result of a generalised erythematous quinine rash followed by desquamation.

As to the hair, it does not appear to have been much affected in the beer-poisoning epidemic. Arsenic is supposed to improve its gloss, just as it is said to improve the coat of horses. On the other hand, loss of hair has been noted in several instances. In this place I must mention a drug which is seldom if ever used now, namely, thallium acetate but which at one time had some vogue in the treatment of the sweats of phthisis. Its use has led to the falling of the hair, not only of the scalp but also of other parts of the body. A generalized alopecia may rapidly ensue without any objective cutaneous morbid manifestations, but the hair grows again when the cause is removed.

I have arrived at the end of my rapid-and in the circumstances necessarily.incomplete-survey. I will now conclude with some general remarks. The raghes may present great variety in their characters; the majority of them in their elementary form are common to other conditions. In onlp a fcw instances practically are they characteristic, as in the case of bromides and of arsenic. In the first-named the elevated lesions I have described are so characteristic as to make a diagnosis possible on them alone. The pigmentation of arsenic is also very typical, especially in the earlier stages, when the minute white areas about the follicles on a dark background are seen. The same may be said of arsenical keratosis.

ETiologY.

The special susceptibility of some individuals goes by the name of idiosyncraey, a term which. like idiopathic, merely burkes the question of rausation. It is always well, therefore. in such cases to pass the various functions and habits of the individual in review in the hope of obtaining a clue, which will sometimes be forthcoming, such as disturbances of the gastro-intestinal tract, constipation (especially in women). catarrhal conditions involving changes in the mucous membranes, dyspepsia in its protean forms. The state of the liver should be inquired into. Disease of that viscus, such as that following in the train of chronic alcoholic poisoning, for instance, may be a factor in the development of skin eruptions. Cardiac disease and renal inadequacy, leading to faulty elimination, are also factors. When albuminuria is present the effects of some drugs may be disastrous. The nervous system, although its share in the production of rashes of all kinds has no doubt been overrated, cannot be neglected. And in this connexion it is well that we should bear in mind the embryological fact that the epidermis with its appendages, including the hair and nails, and the nervous system, central, peripheral and sympathetic, are all developed from the epiblast. This relationship is exemplified in the case of arsenic, which leads to skin, nail, and hair changes, and also to neuritis. In the matter of arsenical pigmentation, again, Leslie Roberts came to the conclusion that the pigment was formed in situ in the epithelial cells, and was not derived from the cutis; and further, that the pigmentation of the palms and soles, though rarely visible clinically, might be present in abundance microscopically. ${ }^{24}$ Speaking of arsenic leads me to point out that this drug is very likely to give rise to morbid alteration of the skin, such as pigmentation, when taken over long periods, whatever the class of patient. This is in contrast with what obtains in the case of other drugs which require favouring conditions. Thus infants and children are especially prone to bromide rashes. Again, some patients are able to take very large doses of iodides for months together without any ill-effects. On the other hand, a very small dose in another patient will give rise to a rash. Moreover, a susceptible patient will react again and again in this way to the same drug, and in some instances, whether it be applied locally or given by the mouth. I have observed, too, that such patients may be susceptible to more than one drug. The intolerance may be extreme, as when a rash follows the mere handling of iodoform gauze. Heard has seen a generalized erythematous rash from $\frac{1}{8}$ gr. doses of quinine. ${ }^{25}$ Again, an individual previously immune to a drug may ultimately become susceptible. This, I take it, is what has been called acquired idiosyncrasy; but it means no doubt that some change has occurred in the organism, a change we cannot grasp, and which we pretend to explain by a word which itself requires explaining. Congenital and hereditary conditions may also play a part. Here, as in the case of idiosyncrasy, it is important to gather patiently all the facts we can,whicin may serve as material for future generalization. In dealing with habits, the associated actions of other toxic products, either introduced into or brewed within the organism, must not be overlooked. Perhaps the internal secretory glands may some day be shown to play a part. An important point is the fact that a drug may occasion an eruption some time after it has been left off.

Diagnosis.

With regard to this, I have already dealt with diagnosis in particular when describing the eruptions themselves. In a general way, whenever an unusual-looking rash comes before you, the possibility of a drug rash should be borne in mind. If the patient has been under your own care, the medication you have prescribed will occur to you. On the other hand; the patient may have taken remedies on his own responsibility, unknown to you, or may consult you for the first time on account of the rash. In ali cases it is important to see as much of the eruption as possible. The duration, distribution, and mode of development, together with a general examination of the patient as to the condition of the various functions, are the points which will help you to arrive at a right conclusion. The duration alone will in some cases exclude the acute exanthemata, and variation from the mode of invasion of the latter will also be of great assistance. The urine should always be examined. Inquiry as to a pre-existing skin disease should be made.

\section{Treatment.}

In the treatment of drug eruptions, the first thing to do is to stop the offending remedy. But even then it must not be forgotten that the eruption caused by bromides and iodides may persist for a time. The next step is to eliminate the drug by the way of the kidneys or bowels. Diuretics are therefore useful, and milk in this respect may be found valuable, both as a diuretic and as a food which gives little work to the organism. Aperients are indicated for intestinal elimination. It is an interesting point to remember that poisons not only act on the skin, but also on the mucous membranes lining the alimentary tract. Külz has shown that when alkaline bromides and iodides are substituted for chlorides, the gastric juice becomes acidified by hydrobromic and hydriodic acid respectively, instead of hydrochloric acid. ${ }^{26}$ A certain amount of diarrhoea in drug rashes should not be interfered with any more than you would suddenly stop a similar condition in albuminuria; it may be a natural effort of the body to get rid of the poison. The exhibition of diuretics and aperients will be governed by the general condition of the patient. It is well-known that potassium iodide helps to get rid of arsenic and mercury by releasing them into the circulation. ${ }^{27}$ But it is well to bear in mind that more harm than good may result from the employment of this method, as is well exemplified in the case of mercury; and that the sudden charging of the blood with the fons et origo mali may lead to an aggravation of the symptoms. It is also imporiant not to push, a drug, which instead of ameliorating a morbid skin condition is doing the distinct contrary. In bromide eruptions, liq. arsenicalis is of assistance. The latter given in association with the bromide will usually in cases of epilepsy prevent the rash of the latter, but not always. The possibility of inducing arsenical keratosis and pigmentation must not be lost sight of. In epilepsy, Féré insists on the part played by intestinal catarrh in the development of bromide rashes; these were avoided, he found, by the use of intestinal antiseptics. When the drug is conveyed through the mother's milk, she must either stop the drug, or the infant must be weaned and artificially reared. Locally, drug eruptions must be treated on the same lines as other skin affections.

\section{Prognosis.}

This is favourable as a rule, but in the case of argyria nothing can be done. In slight and recent cases of arsenical pigmentation, the latter may fade, but little change is to be expected, at any rate for a very long time, in marked ones. Arsenical keratosis is also an obstinate condition. Prognosis would of course be guided by the general condition of the patient. Some cases have terminated fatally, but this is a rare issue.

Pathogenesis.

I may gay at once that the way in which drugs lead to 
morbid cutaneous manifestations is probably more complex than appears on the surface. As in the production of all disease, various factors are at work, some of which are at present unknown. Recent study of the blood and of immunity points the way, I think, in the direction of a solution. ${ }^{2}$ Behrend's view that drug eruptions may be the result of the production of toxins in the body is probably correct in some cases. It receives support from the fact that eruptions may occur some time after the exhibition of the drug. The rashes due to antitoxins may be mentioned in this connexion. The sweat-excretory view was put forward long ago by Trousseau. ${ }^{29}$ Other hypotheses are that drug eruption depend on changes in the tissues themselves or in their vessels. Others rely on the peripheral nerves, on the vasomotor centres, on trophic nerve influence. As to the last named physiologists state there is no proof of the existence of such. Howbeit, it can be safely said at the present juncture that the intimate mechanism of drug eruptions is not known Normally, the tissues are bathed in sodium chloride, but may not the use of bromides and iodides lead to rashes by oubstituting bromine and iodine for the chlorine?

I will conclude with the practical application of a knowledge f drug eruptions. I have already insisted on the part played by zoster in the Manchester epidemic. Sir William Gowers relates an interesting instance bearing on this point. ${ }^{30}$ In 8 case of peripheral neuritis in a young Indian civil servant, arsenical pigmentation gave the clue to his disorder. It was ultimately found that there had been a prolonged attempt to poison the patient in India. A curious fact, too, was that about the commencement of his illness, which had been diagnosed as intermittent fever, he had had an attack of shingles. I need hardly tell you that in India arsenic is largaly used as a poison, and the same custom apparently prevails in other Eastern and semi-Eastern countries. ${ }^{31}$

BIBLIOGRAPHY.

1 Edmund White, Lancet, vol. ii, 1873, p. 8. 2 Alley, cited by Pereira Materia Medica, 3rd ed., 1849, vol. 1, p. 818. 3 Pearson, ciced in Bamue Cooper's Dict. of Pract. Surg., 7th ed., 1838, p. 958, col. 2. 4 J. Hancocke Wathen, Brit. Jour, Derm., vol, x, 1898, p. 95; Trans. Derm. Soc. of G. B.

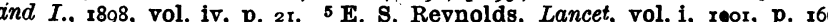
(reprint); 6 Radcliffe Crocker, Dis. of Skin, 3 rd ed.; also same author's Atlas. Radcliffe Crocker, op. cit. 8 Szadek, cited by Julius Müller, Monatsh. $f$ prakt. Derm., vol. Xx, p. 423. 9 Private Case Book C., p. 92. 10 CrichtonBrowne, cited by Radcliffe Crocker, op. cit. 11 Wiglesworth, cited by Radcliffe Crocker, op. cit. 12 Dubreuilh, Presse \$śdicale, No. 40, May 18th, rgor. 13 Vincent, Lancet, vol. i, rgo2, p. 962 ; Pernet, Lancet, ibid., p. 1063 14 Shepherd, of 15 Thomas Hunt, A Guide to the Treatment of Diseases of the Skin, 1871,
p. 22.16 Reynolds, loc. cit. supra (j). 17 W. Murray, Rough Notes p. 22.16 Reynolds, loc. cit. supra (j). $17 \mathrm{~W}$. Murray, Rough Notes 19 Thibierge, loc. cit. supra. 20 Rasch, Dansk Dermatologisk Selskab For handlinger, May 2nd, sgoo. 21 Radeliffe Crocker and Pernet, BRITISH Mmical JoURNaL, vol ii, rgor, p. 8422 Köbner, cited by Berliner, Monats. f. prakt. Derm., vol. Xxxv, p. 137. 23 For Nails see also Pernet. Encyclopaedia Medica, vol. viii, rgor, p. 230 . 24 Brook and Roberts, Brit. Journ. of Derm., xiii, rgor, p. I21. 25 Heard cited by stelwagon in Treatise on Diseases of the Skin, rgo2, p. 428, footnote. ${ }^{26} \mathrm{Külz}$ cited by Dastre in Revue des Deux Mondes, vol. i, rgor, p. 2 ro. ${ }^{27}$ Vide Pernet, British MEdicat Journal, vol, i, rgor, p. 56r, as to Donovan's solution. 28 William $\mathrm{H}$. Welch, BRITISH MEdical JoURNAL, vol. ii, rg02, p. Iro5, especially remarks on Snake Venom, p. Irrr; a]so Burdon Sanderson, Presidential Aduress, Lancet, vol. ii, 1902, p. 1169. 29 Trousseau, Cliniqu Médicale de l'Hótel-Dieu de Paris, vol. i, 1865, p. ז99, and Ed. ${ }^{30}$ Gowers, Lancet, vol. ii, rgor, p. $3175 . \quad 31$ Graves, Studies in Physiology and Medicine, 1863, p. $26 \mathrm{x}$, et seq. The frequency of poisoning and of zoster is mentioned.

\section{DATURA POISONING IN THE FEDERATED MALAY STATES.}

By JOHN D. GIMLETTE, M.R.C.S.ENG., L.R.C.P.LOND., Acting Senior District Surgeon, Perâk, Malay Peninsulı

IT 'has long been known that datura fastuosa, datura stramonium, and some other plants of the nightshade family, such as atropa belladonna and hyoscyamus niger, possess poisonous properties.

\section{Botany of the Daturas.}

The species $D$. fastuosa and $D$, alba are members of the genus datura which are commonly found in the Federated Malay States. They are wild or semi-wild plants, which grow on the refuse land of our native villages or thrive on the borders of cultivated land, in the kitchen gardens, near stables, and elsewhere. These two plants of the Peninsula are identical with the datura fastuosa (Linn.) and the datura alba (Nees) of India, where they are also found more or less commonly with other members of the same genus.

Datura fastuosa (Linn.), the black datura, is generally taken as a type of the tropical varieties of the daturas. It is a quickly growing herbaceous plant belonging to the natural order Solanaceae, about 4 to $6 \mathrm{ft}$. high, with widely-spreading branches and conspicuous trumpet-shaped flowers.

Babitat.-Common almost everywhere, especially when protected. Malay name-"kechubong itam" or "kechubong ulong"; "trong.pungah" in Kedah.

Distribution,-South-Eastern Asia and Malay Archipelago. Leaves broadly ovate, often about 5 to 10 in. long ( 12.5 to $25 \mathrm{~cm}$.), and 4 .in. broad ( $19 \mathrm{~cm}$.) at the widest part, margin repandly toothed, petiole $4 \frac{1}{4} \mathrm{in}$. (xx $\mathrm{cm}$.) long, a pex acute, base unequal, glabrous or sparsely tomentose upper surface dark greyish-green, under surface paler. The fresh leaves exhale a fetid smell when bruised, and have a slightly bitter taste Flowers : axillary on short peduncles about $\frac{1}{2}$ in. $(\mathrm{r} \mathrm{cm}$.) in length, single erect. Calyx tubular, five-angled, five-toothed, teeth reaching about half thelength of the corslla tube. Corolla funnel-shaped (infundibuliform), purple or white without, and white within; fire-lobed, twisted in bud Lobes oblong ovate, cuspidate, length of funnel about 6 in. (15 cm.). Stamens inserted near the base of the tube, included, anthers linear with parallel cells, opening by introrse slits. Ovary two-celled, falsely fourcelled by false septa, ovules attached to both the true and the false septa. style fliform, stigma bilamellate. Fruit an oblong globular capsule, $3 \frac{1}{2}$ in. $(4 \mathrm{~cm}$.) in diameter, spinous, dehiscing by halves, seeçs indefinite embryo with characteristic curvation. Fruit stalk recurring with maturity until the ripe fruit becomes pendent.

Datura alba (Nees), the white datura, kechubong puteh, is a taller plant than the preceding, with trumpet-shaped flowers, either pure white in colour, or yellowish-white tipped with violet. The flower is smaller and more tubular in shape than that of the datura fastuosa, the teeth of the calyx being less than half the size, and lanceolate acuminate in shape. The differences between the two plants, however, are so slight that they can scarcely be classed as being specifically distinct from each other.

Datura alba is the cummon datura of the Federated Malay States, but in certain districts datura fastuosa is said to be the more common of the two. Both plants are found in the Straits Settlements.

Datura stramonium (Linné), owing to its wide distribution in Europe and America, as well as in Asia, the best of all the ten or twelve species which have been recognized, is probably D. stramonium, or the dwarf thorn apple, which, however, so far as I know, does not occur in the Federated Malay States. It is necessary to refer to it, as it has been taken as the type of the temperate or tropical-alpine series, and because of the almost identical toxological significance which is attached to the datura fastuosa, datura albs, and datura stramonium at the present time.

Popular descriptions of the tropical daturas as the black and white kinds has led to a great deal of confusion, it having been often taken for granted, on the authority of natives of India, that the black datura possesses more powerfully poisonous propertics than the white, but of the same nature. No proof of this, however, has yet been given. By reference to the colour of the flowers alone no botanical distinction can be made, and it may be remarked that soil and circumstances may modify the colour of the flower or even double or treble the corolla.

Description of the Datura Seeds.-The seeds, in which the poisonous property chiefly exists, bear some slight resemblance to those of the common chillies (capsicum), and at times have been mistaken for them.

In many instances the light colour and the pungent taste of the latter would be sufficient to make a distinction, but when either is cooked and mixed with food, such as boiled rice recognition by means of the taste alone cannot be relied upon. The resemblance is most marked in the unripe geeds, but a careful comparison of the two kinds shows many morphological points of difference; the datura alba seed is almost reniform in shape, having one end smaller than the other. It has been not altogether fancifully compared to the human ear, but the margin is angular; size about in. (5 millimetres) in length, rather less in width no marked odour; taste slightly bitter; surface somewhat shrivelled except on the two compressed sides; testa tough and rough, being made up of a convoluted series of thick-walled cells, so a rranged as to give a pitted appearance when seen with a lens. Datura seeds in powder may be distinguished by means of the cavernous appearance of their exosperm when seen under the microscope.

The embryo is embedded in a white oily albumen, and curved in a manner peculiar to the genus. By cutting parallel to the flattened side the embryo may be seen by the naked eye to be curved, twisted, and recurved, so as to resemble the head of a shepherd's crook.

A watery decoction of the datura seeds, when placed in the eye, will cause dilatation of the pupil.

The seed of the capsicum is kidney-shaped, a little shorter and wider han that of the datura, pale yellow in colour, uniformly rough, and when 